\title{
Preservation of the rat blood-testis barrier after ligation of the ductuli efferentes, as demonstrated by intra-arterial perfusion with peroxidase
}

\author{
Elsa Anton \\ Centro de Investigaciones en Reproducción, Faculty of Medicine, Paraguay 2155, Piso 10, 1121 \\ Buenos Aires, Argentina
}

\begin{abstract}
Summary. Electron microscope examination of rat testes 1,3 and 7 days after ligation of the ductuli efferentes showed that the horseradish peroxidase tracer penetrated into the basal compartment of the seminiferous tubules, but the marker did not progress beyond the junctional complexes between Sertoli cells. These findings indicate that in spite of the severe morphological changes brought about by ligation, the tight junctions between the Sertoli cells maintain their capacity to act as the testis barrier.
\end{abstract}

\section{Introduction}

The existence of a selective barrier against the passage of substances into the lumen of the seminiferous tubules has been well demonstrated by the differences in chemical composition of the tubular fluid in comparison to the blood and lymph (Setchell, Voglmayr \& Waites, 1969). The most important components of the blood-testis barrier are the typical occluding junctional specializations formed between adjacent Sertoli cells. Those junctions are located near the basal part of the tubules and divide the epithelium in two compartments (Dym \& Fawcett, 1970): (1) the basal compartment containing spermatogonia and preleptotene spermatocytes, and (2) the adluminal compartment containing all the more advanced stages of the germ cells. The presence of the barrier has been shown cytologically by adding lanthanum nitrate to the fixative (Neaves, 1973; Ross, 1977; Osman \& Plöen, 1978) or by injecting horseradish peroxidase intravenously (Aragon \& Lustig, 1973; Willson, Jones, Katsh \& Smith, 1973). Both electron-opaque tracers permitted observation of the intercellular spaces and showed that the transit of the marker from the basal to the adluminal compartment was stopped at the junctions between adjacent Sertoli cells.

Contradictory results on the effects of ligation of the ductuli efferentes on the permeability of the barrier have been reported. Neaves (1973) found leakage of lanthanum nitrate through the Sertoli cell occluding junctions in rats by $24 \mathrm{~h}$ after ligation whereas Ross (1977) presented evidence that in mice the same tracer did not pass through these junctions. Osman \& Plöen (1978) obtained results similar to those of Ross (1977) for rats, $48 \mathrm{~h}$ after ligation.

In the present investigation horseradish peroxidase was applied by direct perfusion through the spermatic artery, to help clarify the effect of ductuli efferentes ligation on the testis barrier of the rat. 


\section{Materials and Methods}

Ligation of the ductuli efferentes was performed unilaterally on 3-5-month-old Wistar rats, as previously described (Anton, 1979). At 1, 3 and 7 days after ligation the animals (4/group) were anaesthetized by an intraperitoneal injection of urethane $(120 \mathrm{mg} / 100 \mathrm{~g}$ body weight) and the testis on the side of ligation was immediately perfused through the internal spermatic artery (R. Ponzio, E. Anton, unpublished observation) with Eagle's L medium (Difco Laboratories, Detroit, U.S.A.) containing $0.05 \%$ heparin and a total amount of $6 \mathrm{mg}$ horseradish peroxidase (Type II, Sigma Chemical Co., Missouri, U.S.A.). The perfusion was for $15 \mathrm{~min}$ at a constant rate of $0.21 \mathrm{ml} / \mathrm{g}$ testis weight/min using a Compact Infusion Pump (Harvard). Perfusion of peroxidase was followed by perfusion for $20 \mathrm{~min}$ at the same rate with $5 \%$ glutaraldehyde in 0.1 M-cacodylate buffer, pH 7.4. The testis was then cut into slices $1 \mathrm{~mm}$ thick, immersed in fresh fixative for $2 \mathrm{~h}$, and washed overnight in the same buffer containing $0.25 \mathrm{M}$-sucrose. Sections 50-70 $\mu \mathrm{m}$ thick were obtained with a Smith Farquhar tissue sectioner and developed for peroxidase with 3,3-diaminobenzidine according to the method of Graham \& Karnovsky (1966). Post-fixation was carried out for $2 \mathrm{~h}$ in a solution of $2 \% \mathrm{OsO}_{4}$ and $3 \%$ potassium ferrocyanide, and the sections were embedded in epoxy resin (Maraglas 655: Polysciences Inc, Warrington, U.S.A.). Ultrathin sections were cut on a Porter-Blum microtome and the grids were examined without further staining in a Zeiss EM-9 A electron microscope.

The contralateral testis (unoperated side) was used as the control and was processed in the same way as the other testis.

\section{Results}

Control testis. There were no differences in the control testes for the rats of different ages. The electron-opaque marker infused directly into the spermatic artery was observed around large and small vessels. Although peroxidase was washed out of the vascular lumen, it remained surrounding the endothelial cells, in the perivascular spaces, and between the lymphatic endothelium and the myoid layer (Pl. 1, Figs 1 and 2). The cytoplasm of the myoid cells showed no reaction except for the presence of multiple pinocytotic vesicles near the surface of the plasma membrane. The two basal membranes that form part of the lamina propria presented a strong peroxidase reaction (PI. 1, Fig. 1). In some tubules the penetration of the marker was restricted by junctions at the level of the myoid cells; in others, the peroxidase leaked through that barrier and penetrated into the intercellular spaces which separate spermatogonia and preleptotene spermatocytes from Sertoli cells. However, the marker was never observed beyond the typical occluding junctional complexes between the Sertoli cells (Pl. 1, Fig. 3).

Experimental testis. There were no changes in the distribution of peroxidase at 1, 3 or 7 days after ligation of the ductuli efferentes, and that distribution was similar to that observed in the control testis. At 1 day after ligation the morphology of the seminiferous tubules was still well preserved. As observed in the control testis, the penetration of peroxidase into the basal compartment was partly restricted by the myoid cell junctions but the tracer frequently surrounded spermatogonia and preleptotene spermatocytes, indicating more penetration through the myoid layer (PI. 2, Fig. 4). In the intercellular spaces, however, peroxidase advanced only as far as the typical Sertoli-Sertoli junctions and was never found on the adluminal side of these junctions (PI. 2, Figs 5 and 6). Similar results were observed 3 days after ligation although multiple vacuoles were present in the cytoplasm of the Sertoli cells.

The interstitial distribution of peroxidase was similar 7 days after ligation. In the seminiferous tubules, the Sertoli cells contained cytoplasmic alterations such as numerous vacuoles of variable size that occupied large areas of the cytoplasm (Pl. 3, Fig. 7); however, the junctional specializations still did not permit the passage of peroxidase to the adluminal 

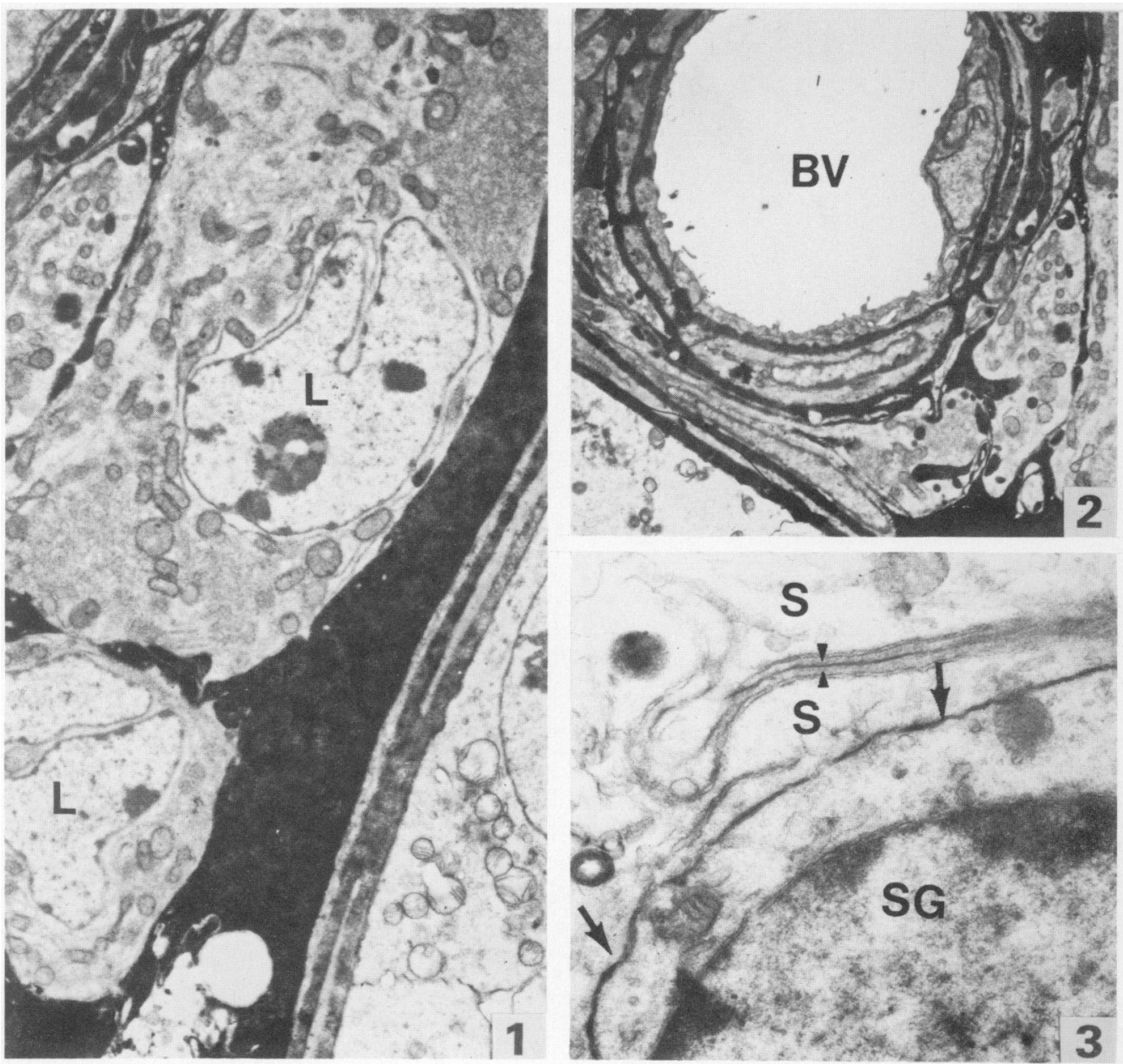

Figures 1-3 are of unstained sections of the control testis, peroxidase reaction.

Fig. 1. Interstice showing heavy infiltration of peroxidase in the lymphatic vessel and around Leydig cells (L). At the lower right part of the picture it is possible to observe a portion of the lamina propria of a seminiferous tubule; the basal lamina shows a strong peroxidase reaction. $\times 5500$.

Fig. 2. Lumen of an interstitial blood vessel (BV) devoid of reaction; the perivascular and peritubular spaces show heavy infiltration of peroxidase. $\times 3500$.

Fig. 3. Electron micrograph of one spermatogonium (SG) and two Sertoli cells (S). There is reaction in the intercellular space between spermatogonium and the Sertoli cell (arrows) but the junctional specialization between the Sertoli cells (arrowheads) is devoid of peroxidase. $\times 20000$. 

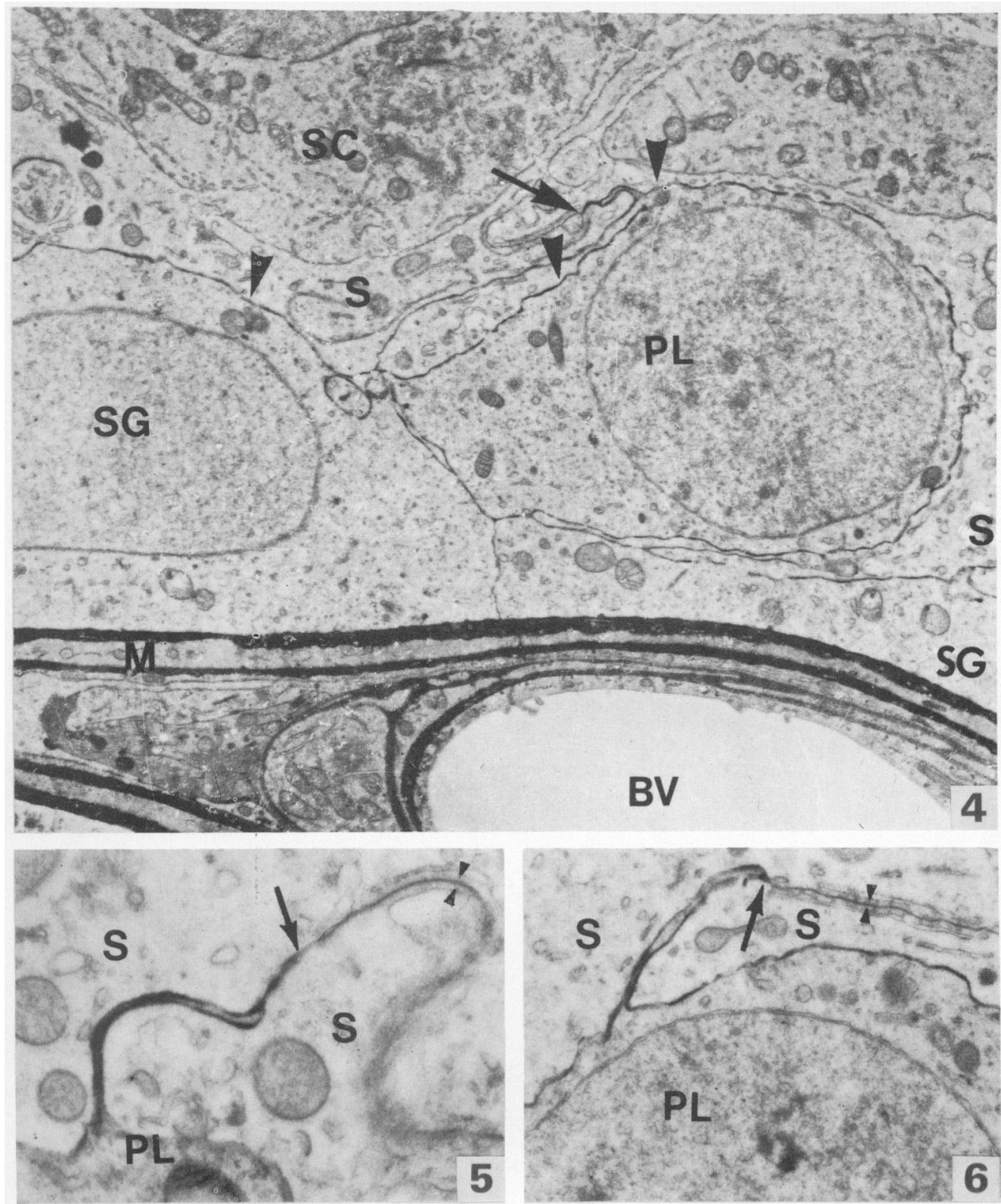

Figures 4-6 are of unstained sections of testis 1 day after ligation of the ductuli efferentes, peroxidase reaction.

Fig. 4. Portion of the periphery of a seminiferous tubule. The peroxidase has penetrated into the tubule; the arrowheads show the reaction in the intercellular spaces between a spermatogonium (SG) and Sertoli cells (S), and between a preleptotene spermatocyte (PL) and Sertoli cells (S). The arrow indicates the junctional specialization. SC: pachytene spermatocyte. BV: blood vessel. $\mathrm{M}$ : myoid cells. $\times 7000$.

Figs 5 and 6. Peroxidase is seen around preleptotene spermatocytes (PL) and between adjacent Sertoli cells (S) but its advance stops (arrows) near the typical junctional specializations (arrowheads). Fig. 5, × 14 000; Fig. 6, × 14500 . 


\section{PLATE 3}

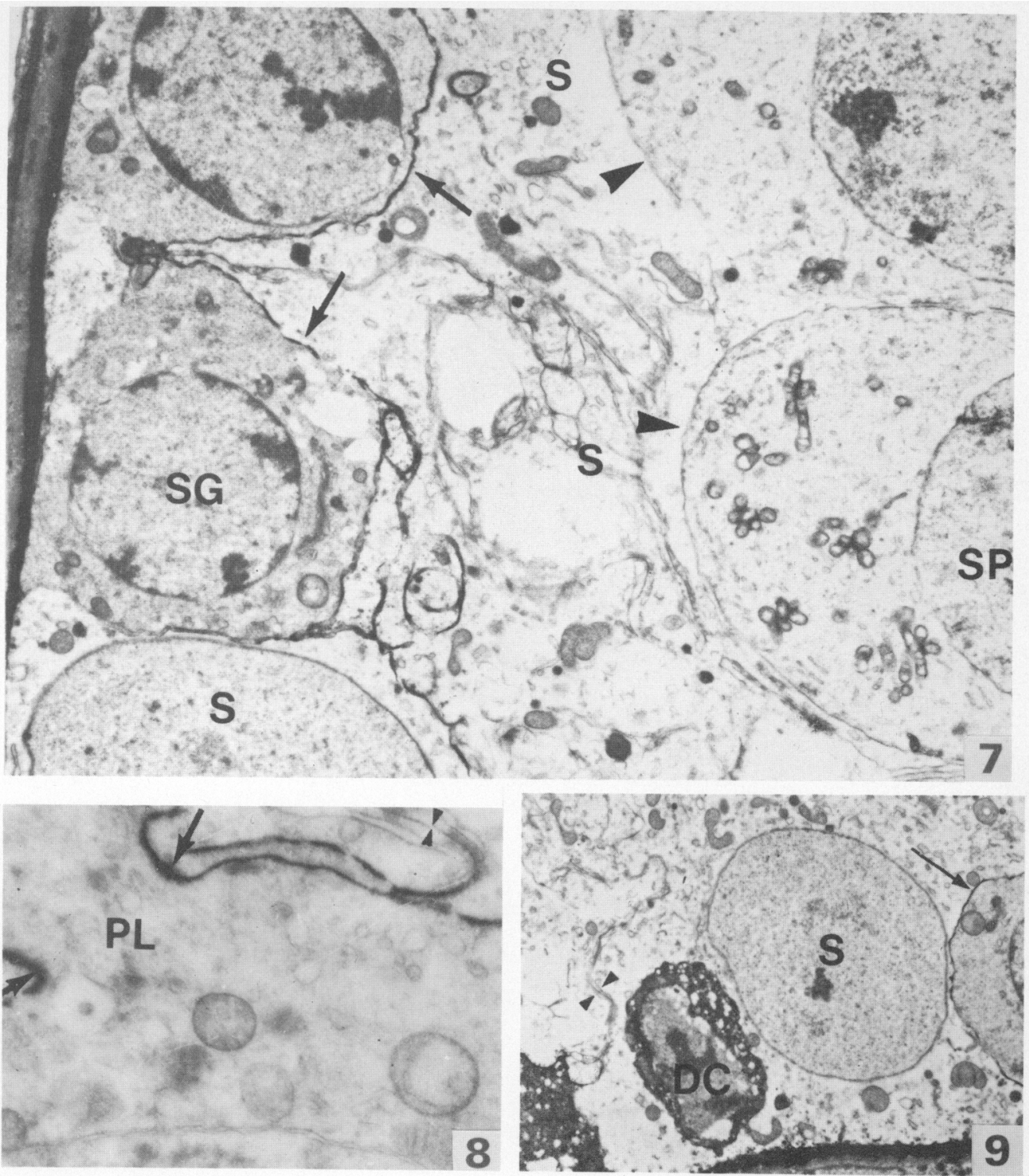

Figures 7-9 are of unstained sections of testis 7 days after ligation of the ductuli efferentes, peroxidase reaction.

Fig. 7. Part of a seminiferous tubule showing spermatogonia (SG) and Sertoli cells (S) surrounded by peroxidase, but only in the basal compartment. The pachytene spermatocytes (SP)-Sertoli cell spaces in the adluminal compartment are devoid of reaction (arrowheads) whereas spermatogonia-Sertoli cells spaces show the reaction (arrows). Although the cytoplasm of the Sertoli cells exhibits alterations the peroxidase has not progressed beyond the Sertoli cell junctional specialization. $\times 5000$.

Fig. 8. Portion of a bridge between preleptotene spermatocytes (PL). A dense reaction is seen in the preleptotene spermatocyte-Sertoli cell space (arrows) but there is no reaction at the Sertoli cell junctional specialization (arrowheads). $\times 22000$.

Fig. 9. Basal portion of a seminiferous tubule showing intense peroxidase reaction in the basal lamina and in the cytoplasmic matrices of 2 degenerating cells (DC), presumed to be spermatogonia or preleptotene spermatocytes. There is reaction product in the preleptotene spermatocyte-Sertoli cell (S) space (arrow) but none at the junctional specialization (arrowheads). $\times 3000$. 
compartment (Pl. 3, Fig. 8). The spermatogonia as well as the preleptotene spermatocytes were outlined by peroxidase (Pl. 3, Fig. 7). Mutiple giant cells were frequently found in the adluminal compartment, but the marker was never observed beyond the tight junctions of the Sertoli cells.

Occasionally peroxidase appeared in the cytoplasmic matrices of degenerating cells (Pl. 3, Fig. 9). Although the identification of those cells was not easy due to the severity of the necrotic process, they were presumed to be spermatogonia or preleptotene spermatocytes because of their shape and size but principally because they were always localized in the basal compartment. The adjacent Sertoli cells neither contained peroxidase nor showed signs of degeneration.

\section{Discussion}

The remarkable stability and resistance of the Sertoli cell tight junctions to various experimental procedures has been reported by several investigators. In experiments with hypertonic lithium chloride (Gigula, Fawcett \& Aoki, 1976) or hypertonic fixative (Russell, 1977) it was observed that whereas the Sertoli cells remained attached to the base of the tubule the spermatogonia appeared shrunken and detached from the basal lamina; furthermore, in the adluminal compartment the cells were not affected, thus demonstrating the resistance of the Sertoli cell junctional specialization to osmotic shock.

Studies with lanthanum nitrate have shown that even after severe testicular damage, such as that observed in varicocoele in man (Cameron, Snydle, Ross \& Drylie, 1980) or experimental cryptorchidism in rats (Hagenäs, Plöen, Ritzen \& Ekwall, 1977), the integrity of the blood-testis barrier is preserved. In the present investigation, advantage was taken of the fact that perfusion through the spermatic artery allows a very rapid and efficient distribution of peroxidase in the testicular tissue. Even after very long periods of ligation ( 7 days compared to the 12-h period of Ross (1977) or the 2-day period of Osman \& Plöen (1978)) the advance of peroxidase was stopped abruptly at the junctions between Sertoli cells, demonstrating that the blood-testis barrier was preserved. Peroxidase was found in the cytoplasmic matrix of some spermatogonia and preleptotene spermatocytes which displayed intense necrotic changes. The penetration of peroxidase into the cytoplasm of some cells has been reported (Brightman, Klatzo, Olsson \& Reese, 1970; Willson et al., 1973) and it was ascribed either to artefacts of tissue processing (Willson et al., 1973) or to damage of the plasma membrane (Brightman et al., 1970). The control and the experimental testes were processed in the same way in the present work, but peroxidase was never found in the cytoplasm of control spermatogonia or preleptotene spermatocytes, although it did appear in the corresponding cells of experimental testis. It seems probable that the necrotic process suffered by the tissues in the experimental testis affected the plasma membrane, thus allowing the entrance of the marker into these cells. The fact that Sertoli cells showed neither necrotic signs nor penetration of peroxidase confirms the resistance of their tight occluding junctions and could, perhaps, explain the notable endurance of the blood-testis barrier.

\section{References}

Anton, E. (1979) Early ultrastructural changes in the rat testis after ductuli efferentes ligation. Fert. Steril. 31, 187-194.

Aragon, J.A. \& Lustig, L. (1973) Uptake of horseradish peroxidase by the testis and epididymis of mice. $J$. Reprod. Fert. 33, 189-195.

Brightman, M.W., Klatzo, I., Olsson, Y. \& Reese, T.S. (1970) The blood-brain barrier to proteins under normal and pathological conditions. J. Neurol. Sci. 10, 215-239.
Cameron, D.F., Snydle, F.E., Ross, M.H. \& Drylie, D.M. (1980) Ultrastructural alterations in the adluminal testicular compartment in men with varicocele. Fert. Steril. 33, 526-533.

Dym, M. \& Fawcett D.W. (1970) The blood-testis barrier in the rat and the physiological compartmentation of the seminiferous epithelium. Biol. Reprod. 3, 308-326.

Gigula, N.B., Fawcett, D.W. \& Aoki, A. (1976) The Sertoli cell occluding junctions and gap junctions in 
mature and developing mammalian testis. Devl Biol. 50, 142-168.

Graham, R.C. \& Karnovsky, M.J. (1966) The early stages of absorption of injected horseradish peroxidase in the proximal tubules of mouse kidney: ultrastructural cytochemistry by a new technique. $J$. Histochem. Cytochem. 14, 291-302.

Hagenäs, L., Plöen, L., Ritzén, E.M. \& Ekwall, H. (1977) Blood testis barrier: maintained function of inter-Sertoli cell junctions in experimental cryptorchidism in the rat, as judged by a simple lanthanumimmersion technique. Andrologia 9, 250-254.

Neaves, W.B. (1973) Permeability of Sertoli tight junctions to lanthanum after ligation of ductus deferens and ductuli efferentes. J. Cell Biol. 59, 559-572.

Osman, D.I. \& Plöen, L. (1978) The terminal segment of the seminiferous tubules and the blood-testis barrier before and after efferent ductule ligation in the rat. Int. J. Androl. 1, 235-249.

Ross, M.H. (1977) Sertoli-Sertoli junctions and Sertolispermatid junctions after efferent ductule ligation and lanthanum treatment. Am. J. Anat. 148, 49-55.

Russell, L. (1977) Movement of spermatocytes from the basal to the adluminal compartment of the rat testis. Am. J. Anat. 148, 313-328.

Setchell, B.P., Voglmayr, J.K. \& Waites, G.M.H. (1969) A blood-testis barrier restricting passage from blood into rete testis fluid but not in lymph. J. Physiol., Lond. 200, 73-85.

Willson, J.T., Jones, N.A., Katsh, S. \& Smith, S.W. (1973) Penetration of the testicular-tubular barrier by horseradish peroxidase induced by adjuvant. Anat. Rec. 176, 85-100.

Received 24 November 1981 